\title{
Effect of Abdominal Electrical Muscle Stimulation Training With and Without Superimposed Voluntary Muscular Contraction on Lumbopelvic Control
}

\author{
Ui-Jae Hwang, Sung-Hoon Jung, Hyun-A Kim, Jun-Hee Kim, and Oh-Yun Kwon
}

\begin{abstract}
Context: Electrical muscle stimulation (EMS) was designed for artificial muscle activation or superimposed training. Objectives: To compare the effects of 8 weeks of superimposed technique (ST; application of electrical stimulation during a voluntary muscle action) and EMS on the cross-sectional area of the rectus abdominis, lateral abdominal wall, and on lumbopelvic control. Setting: University research laboratory. Design: Randomized controlled trial. Participants: Fifty healthy subjects were recruited and randomly assigned to either the ST or EMS group. Intervention: The participants engaged with the electrical stimulation techniques (ST or EMS) for 8 weeks. Main Outcome Measures: In all participants, the cross-sectional area of the rectus abdominis and lateral abdominal wall was measured by magnetic resonance imaging and lumbopelvic control, quantified using the single-leg and double-leg lowering tests. Results: There were no significant differences in the cross-sectional area of the rectus abdominis (right: $P=.70$, left: $P=.99$ ) or lateral abdominal wall (right: $P=.07$, left: $P=.69$ ) between groups. There was a significant difference between groups in the double-leg lowering test $(P=.03)$, but not in the single-leg lowering test $(P=.88)$. There were significant differences between the preintervention and postintervention in the single-leg $(P<.001)$ and double-leg lowering tests $(P<.001)$. Conclusions: ST could improve lumbopelvic control in the context of athletic training and fitness.
\end{abstract}

Keywords: electrical stimulation, magnetic resonance imaging, cross-sectional area

Electrical muscle stimulation (EMS) uses a variety of electrical wave forms to artificially stimulate or superimpose training innervated muscles. EMS has been applied for muscle strengthening, facilitation of muscle contraction and motor control, and maintenance of muscle size and strength during prolonged immobilization in many rehabilitation settings. ${ }^{1-4}$ In addition, EMS programs have been used to improve muscle strength in healthy individuals, and muscle performance in athletes..$^{5-10}$

Neuromuscular adaptations resulting from EMS training in both healthy and diseased muscles can be as large as, but are rarely greater than, those resulting from voluntary contractions (VCs). ${ }^{11,12}$ Previous studies that compared the effects of different training methods showed that EMS induced either less than, ${ }^{13,14}$ or a similar amount of, ${ }^{15-17}$ neuromuscular adaptation compared with $\mathrm{VC}$ in healthy subjects. There is still controversy regarding whether EMS or VC is more effective, but they could also be considered as complementary stimuli that induce different physiological effects; for example, there is a

(C) 2020 The Authors. Published by Human Kinetics, Inc. This is an Open Access article distributed under the terms of the Creative Commons Attribution License CC BY NC 4.0, which permits unrestricted noncommercial use, distribution, and reproduction in any medium, provided the original work is properly cited, the new use includes a link to the license, and any changes are indicated. See http:// creativecommons.org/licenses/by-nc/4.0. This license does not cover any third-party material which may appear with permission in the article. For commercial use, permission should be requested from Human Kinetics, Inc., through the Copyright Clearance Center (http://www.copyright.com).

Hwang, Jung, H.A. Kim, and J.K. Kim are with the Department of Physical Therapy, Graduate School, Yonsei University, Wonju, South Korea. Kwon is with the Laboratory of Kinetic Ergocise Based on Movement Analysis, Department of Physical Therapy, Graduate School, College of Health Sciences, Yonsei University, Wonju, South Korea. Kwon (kwonoy@yonsei.ac.kr) is corresponding author. tendency for EMS to reverse the order of the motor unit recruitment observed with VC. . $^{18,19}$

By superimposing VC and EMS (superimposed technique [ST]; application of EMS during voluntary muscle action), the physiological effects attributed to each stimulus may accumulate. ${ }^{20}$ Because EMS mainly stimulates large motor units, whereas VC first recruits small motor units, it is possible that ST can recruit more motor units than EMS or VC alone. ${ }^{20}$ Previous studies of the effects of ST have typically concentrated on isolated muscle groups, such as the quadriceps, ${ }^{21-25}$ to increase muscle strength and muscle size and improve motor performance in sport. Regarding the abdominal muscles, previous studies investigated the effects of ST on their isometric strength and endurance. ${ }^{26}$

Strength programs that focus on trunk stabilization strengthen the abdominal muscles, improve motor control, and decrease low back pain. ${ }^{27-29}$ The abdominal muscles involved in trunk stabilization include the transverse abdominal (TrA) and internal oblique (IO) muscles, whereas the external oblique and rectus abdominis (RA) muscles mainly contribute to lumbopelvic control (LC). ${ }^{29-32}$ LC is generally considered to provide a foundation for lumbopelvic dynamic control; this allows for optimal control and transfer of load, which is transferred throughout the kinetic chain during functional movements. ${ }^{3-37}$ Instantaneous and efficient LC functioning requires successful integration of sensorimotor control. ${ }^{28,35,37-40}$

It has been postulated that the abdominal musculature of most people is atrophied due to the effects of the sedentary modern lifestyle. ${ }^{41-43}$ The RA and lateral abdominal wall (LAW) muscles (external oblique, IO, and TrA) play an important role, not only in appearance, muscle strength, and endurance, but also in LC. Although various electrical stimulation devices for the abdominal muscles are being marketed to the general public, there is still a lack of research on whether ST alone, EMS alone, or both in combination is most effective for improving abdominal functions. Thus, the purpose of this study 


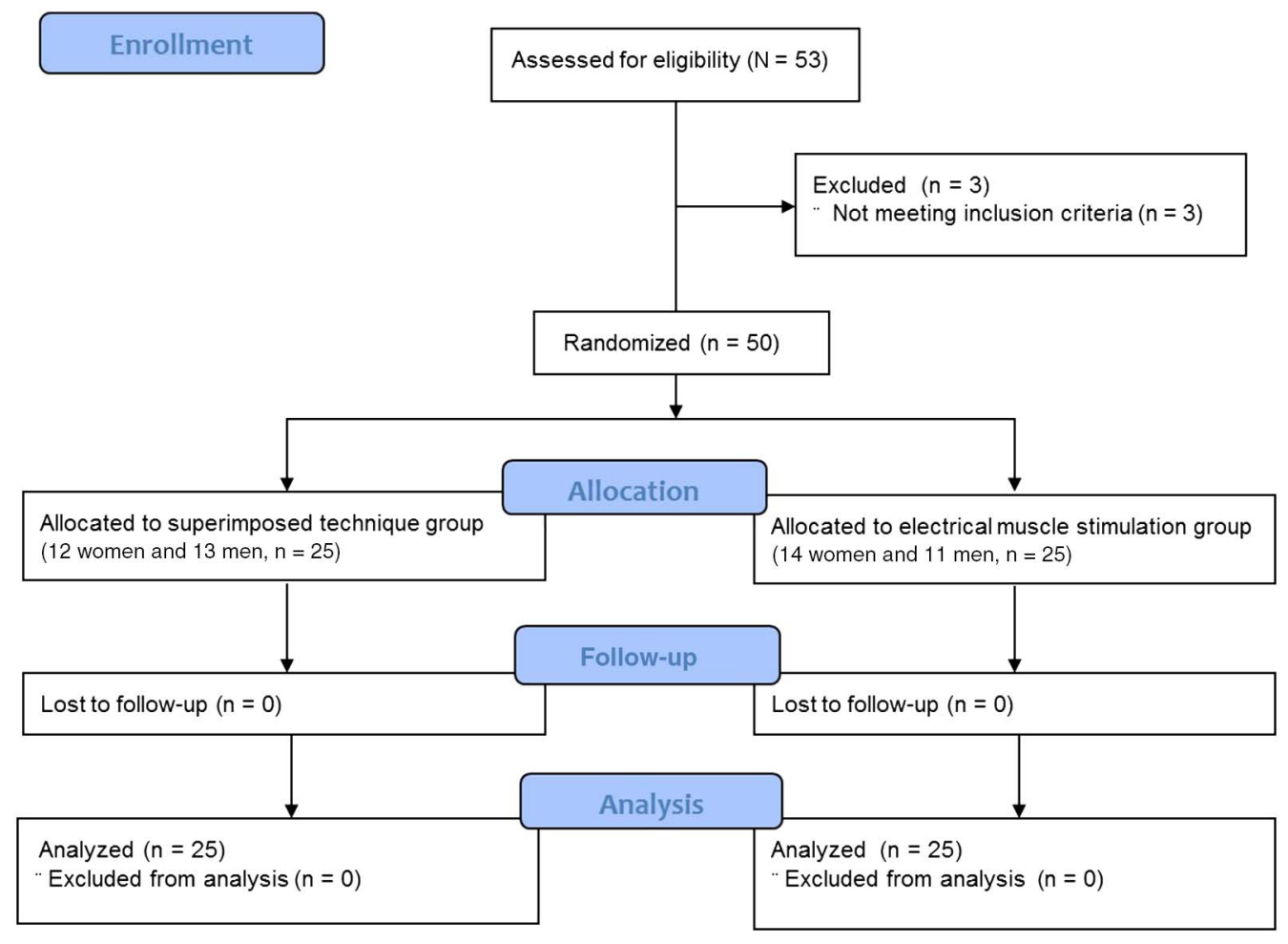

Figure 1 - Flow diagram of our randomized trial between groups.

was to compare the effects of 8 weeks of ST and EMS abdominal muscle training on muscle size and LC. We hypothesized that ST would be more effective than EMS for improving muscle size and LC.

\section{Methods}

\section{Subjects}

The sample size was determined a priori using $\mathrm{G}^{*}$ Power software (version 3.1.3; University of Trier, Trier, Germany) ${ }^{44}$ based on the data of a pilot study that included 3 participants per group (ST and EMS). The sample size calculation was based on a power of 0.95 , alpha value of .05 , and effect size $(f)$ of 1.23 ; more than 10 subjects were found to be required per group. Fifty healthy subjects without a history of hernia, cardiovascular disease, neurological disease, musculoskeletal dysfunction of the lumbar spine or pelvis, or claustrophobia were recruited and randomly assigned to the ST or EMS group (Figure 1 and Table 1). Participants with cardiac pacemakers or other electronic implants were excluded from the EMS group. Individuals who had an aversion to the sensation of electrical stimulation were excluded from the study. Before the study, all subjects were briefed on the procedures thereof and signed an informed consent form approved by the institutional review board.

\section{Electrical Muscle Stimulation Training}

The EMS was applied to the abdominal muscles using a SIXPAD Abs Belt (MTG, Nagoya, Japan). The EMS device consisted of a contoured, flexible, soft silicone belt with electrodes that were connected to the stimulator without externally visible leads or detachable gel pads. The EMS device delivered biphasic, symmetric pulses of 2 to $20 \mathrm{~Hz}$, and pulse frequency and duration were controlled using a program that stimulated the RA and LAW muscles (mean intensity, 30.06 [7.47] $\mathrm{mA}$ [range: 18.28$41.83 \mathrm{~mA}])$. Subjects were encouraged to increase the amplitude on the stimulator to elicit strong contractions of the abdominal muscles (within tolerable limits). Subjects were instructed not to perform volitional contractions during electrical stimulation and to consistently attach the center of the EMS device over the umbilicus.

Table 1 Subject Characteristics

\begin{tabular}{|c|c|c|c|c|c|c|c|}
\hline \multirow[b]{2}{*}{ Characteristics } & \multicolumn{3}{|c|}{ ST group } & \multicolumn{3}{|c|}{ EMS group } & \multirow[b]{2}{*}{$P$} \\
\hline & Total $(n=25)$ & Men $(n=13)$ & Women $(n=12)$ & Total $(n=25)$ & Men $(n=11)$ & Women $(n=14)$ & \\
\hline Age (SD), y & $25.0(3.3)$ & $25.7(3.6)$ & $24.3(2.7)$ & $25.2(2.0)$ & $26.4(1.8)$ & $24.2(1.7)$ & .39 \\
\hline Body height (SD), cm & $169.0(8.9)$ & $176.7(3.1)$ & $160.8(4.2)$ & $166.3(8.7)$ & $173.5(4.5)$ & $160.7(6.8)$ & .30 \\
\hline Body mass (SD), kg & $66.3(15.3)$ & $77.1(12.5)$ & $54.6(7.0)$ & $64.3(13.7)$ & $77.4(8.1)$ & $53.9(5.8)$ & .54 \\
\hline BMI (SD), $\mathrm{kg} / \mathrm{m}^{2}$ & $23.0(3.6)$ & $24.7(3.5)$ & $21.1(2.7)$ & $23.0(3.5)$ & $25.8(3.2)$ & $20.9(1.7)$ & .89 \\
\hline
\end{tabular}

Abbreviations: BMI, body mass index; EMS, electrical muscle stimulation; ST, superimposed technique. 


\section{Superimposed Technique Training}

The ST subjects were electrically stimulated using the same EMS device and training protocol as in the EMS group. The mean contraction intensity was $33.30(0.78) \mathrm{mA}$ (range: 18.28 $41.83 \mathrm{~mA})$. In addition, they performed VCs via 2 abdominal crunch cycles over a 10 -second period $(1$ cycle $=3 \mathrm{~s}$ of tetanic stimulation followed by a 2-s pause). For abdominal crunches, the subject was supine in the standard sit-up position, with the knees bent at $90^{\circ}$ and the hands folded across the chest. The subject contracted the abdominal muscles by drawing the belly button inward (toward the spine), and then raised the head and shoulders upward until the shoulder blades cleared the table. Subjects held this position for 10 seconds and then returned to the starting position. The subjects were asked to perform 10 sets of abdominal crunches in accordance with the EMS training protocol for 4 weeks, followed by 15 sets for another 4 weeks.

\section{Magnetic Resonance Imaging Assessment of Abdominal Muscle Size}

Subjects were screened for contraindications to magnetic resonance imaging (MRI) by a medical practitioner before the study assessment. Subjects with metal implants or claustrophobia were excluded from the study. Subjects removed any metal objects on the body prior to the assessment and were then placed in a supine position. The MRI scans were obtained using a $1.5 \mathrm{~T}$ scanner (Magnetom Avanto; Siemens, Erlangen, Germany). Ten contiguous 5-mm-thick slices centered on the L3-L4 discs were acquired with the patient in a relaxed state, with the breath held at midexpiration. ${ }^{45,46}$ Measurements of abdominal muscle size on MRI included the cross-sectional area (CSA) of the RA and LAW (intrareliability; intraclass coefficient $[\mathrm{ICC}]=.892$ ). The MRI images were archived for later analysis using a measurement software package on a laptop computer.

\section{Measurement of LC: Single-Leg and Double-Leg Lowering Tests}

The single-leg and double-leg lowering tests were used to assess LC by measuring the subject's ability to control the spine during movements of the lower limbs. ${ }^{29,32,33,47,48}$ While in the supine position, the subject flexed the hip and knee to $90^{\circ}$. A Smart KEMA pressure sensor (KOREATECH Co, Ltd, Seoul, Korea) was set to $40 \mathrm{~mm} \mathrm{Hg}$ and placed below the lordotic curvature of the spine between L1 and S1, with the hip and knee in $90^{\circ}$ of flexion. Using its strap, the Smart KEMA motion sensor (KOREATECH Co, Ltd) was attached to the thigh between the greater trochanter and knee joint. During performance of the abdominal drawing-in maneuver, the pressure on the sensor was increased by $10 \mathrm{~mm} \mathrm{Hg}$. Subjects were asked to hold the lumbopelvic position by contracting the abdominal muscles while slowly lowering one or both legs to the supporting surface. One or both leg lowering (hip extension) angles were measured with a motion sensor, and LC was defined as the moment when the pressure sensor reading decreased below $50 \mathrm{~mm}$ $\mathrm{Hg}$ (Figure 2). Because the abdominal muscles are necessary for LC during leg motion, with greater leg lowering angle, the control of the lumbopelvis is improved. The leg lowering angle was normalized to subject height (in meters) $\times$ mass (in kilograms) for statistical analysis. The mean single-leg $(\mathrm{ICC}=.979)$ and double-leg lowering angles $(\mathrm{ICC}=.867)$ for 3 trials were used in the data analysis.
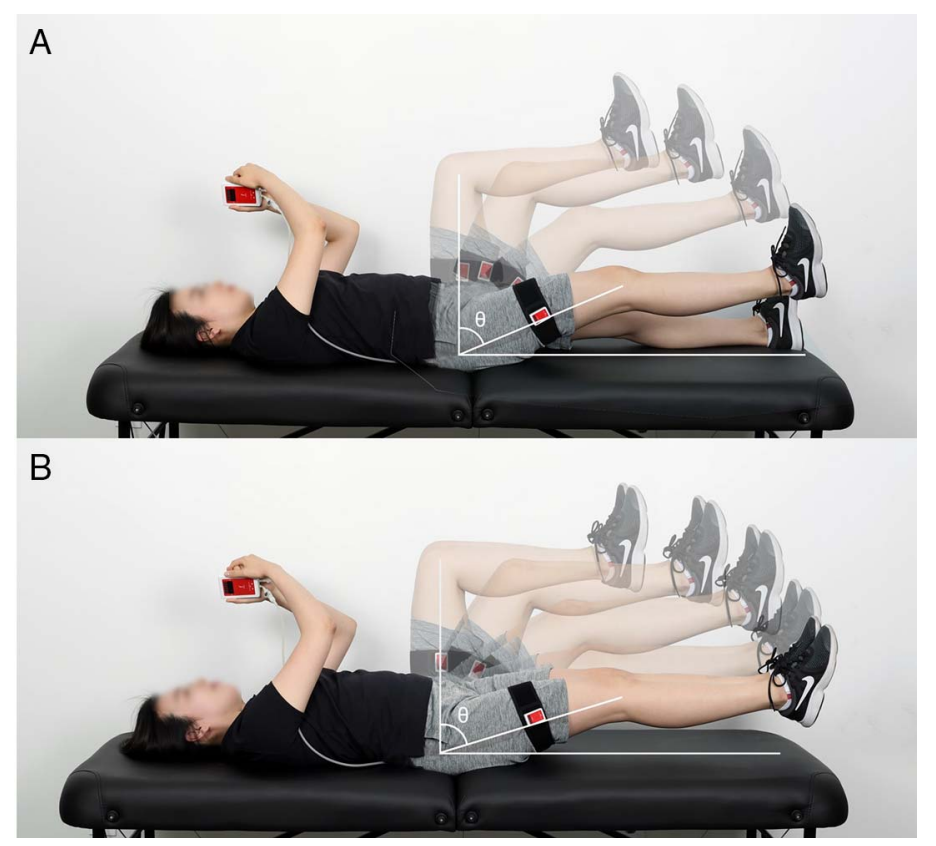

Figure 2 - Measurements of the (A) single-leg lowering test and (B) double-leg lowering test.

\section{Procedures}

This study was performed over a 6-month period from January to June 2018. During a preliminary session, all participants underwent MRI in the radiology center for baseline measurement of the CSA of the RA and LAW, and for a baseline assessment of LC. The order of the 3 tests (single-leg lowering test on either side and the double-leg lowering test) was randomized using an online program (http://www.randomization.com).

Electrical muscle stimulation and ST training were performed twice a day for 23 minutes for 8 weeks. Adherence to this schedule was confirmed by telephone every day, and the participants were encouraged to perform EMS training on at least 5 days per week. ${ }^{49}$ The subjects were instructed not to perform additional fitness training or abdominal muscle exercises during the study. For all participants, the instrument settings remained the same as during the preliminary session.

\section{Statistical Analysis}

All statistical analyses were conducted using SPSS software (version 18.0; SPSS Inc, Chicago, IL). The Kolmogorov-Smirnov $Z$ test was used to verify the normality of the data distribution. Descriptive statistics were used to analyze the abdominal muscle size and LC data, which were normally distributed. The $\operatorname{ICC}(3,1)$ model was used to assess intrarater reliability regarding measurements of muscle size and LS. Analysis of covariance was used to compare the groups before and after the intervention, with the baseline values used as covariates. Data are presented as mean (SD). Effect sizes $(r)$ and confidence intervals (CIs) for the primary outcomes were calculated to determine the clinical significance of the data. The $r$ was constrained between 0 (no correlation) and 1 (perfect correlation); in this study, $0 \leq r<.1$ was classified as no effect, $.1 \leq r<.3$ as a small effect, $.3 \leq r<.5$ as a moderate effect, and $r \geq .5$ as a large effect. ${ }^{50}$ For post hoc analyses, a paired $t$ test was performed to determine premeasurement versus postmeasurement differences in each group. The significance level was set at $P<.05$ for all analyses. 
Table 2 Comparison of Changes in Abdominal Muscle Size and LC, Preintervention Versus Postintervention, in the ST and EMS Groups

\begin{tabular}{|c|c|c|c|c|c|c|c|}
\hline Category & Variables & Side & Session & ST group & EMS group & $\begin{array}{c}\text { Mean change } \\
(95 \% \mathrm{Cl})\end{array}$ & $\begin{array}{c}\text { Effect } \\
\text { size }\end{array}$ \\
\hline \multirow{8}{*}{$\begin{array}{l}\text { Abdominal muscle } \\
\text { size, } \mathrm{cm}^{2}\end{array}$} & \multirow[t]{4}{*}{ CSA of RA (SD) } & \multirow[t]{2}{*}{ Right } & Pre & $5.32(2.01)$ & $5.18(1.61)$ & \multirow{2}{*}{$-1.23(-1.49$ to -0.97$)$} & \multirow[t]{2}{*}{0.66} \\
\hline & & & Post & $6.51(2.45)$ & $6.45(2.00)$ & & \\
\hline & & \multirow[t]{2}{*}{ Left } & Pre & $5.41(2.04)$ & $5.27(1.72)$ & \multirow[t]{2}{*}{$-1.13(-1.41$ to -0.85$)$} & \multirow[t]{2}{*}{0.59} \\
\hline & & & Post & $6.55(2.33)$ & $6.39(2.27)$ & & \\
\hline & \multirow[t]{4}{*}{ CSA of LAW (SD) } & \multirow[t]{2}{*}{ Right } & Pre & $21.98(7.94)$ & $20.48(6.87)$ & \multirow[t]{2}{*}{$-1.34(-1.80$ to -0.88$)$} & \multirow[t]{2}{*}{0.43} \\
\hline & & & Post & $22.90(7.79)$ & $22.24(7.46)$ & & \\
\hline & & \multirow[t]{2}{*}{ Left } & Pre & $21.90(7.26)$ & $20.47(6.98)$ & \multirow[t]{2}{*}{$-1.78(-2.35$ to -1.20$)$} & \multirow[t]{2}{*}{0.45} \\
\hline & & & Post & $23.59(7.91)$ & $22.34(7.32)$ & & \\
\hline \multirow[t]{4}{*}{$\mathrm{LC}, \mathrm{deg} / \mathrm{kg} \cdot \mathrm{m}$} & \multirow[t]{2}{*}{ Single-leg lowering test (SD) } & \multirow[t]{2}{*}{-} & Pre & $0.46(0.27)$ & $0.42(0.25)$ & \multirow[t]{2}{*}{$-0.13(-0.20$ to -0.07$)$} & \multirow[t]{2}{*}{0.25} \\
\hline & & & Post & $0.58(0.30)$ & $0.56(0.27)$ & & \\
\hline & \multirow[t]{2}{*}{ Double-leg lowering test (SD) } & \multirow[t]{2}{*}{-} & Pre & $0.23(0.18)$ & $0.24(0.19)$ & \multirow[t]{2}{*}{$-0.11(-0.16$ to -0.07$)$} & \multirow[t]{2}{*}{0.35} \\
\hline & & & Post & $0.39(0.22)$ & $0.30(0.19)$ & & \\
\hline
\end{tabular}

Abbreviations: CI, confidence interval; CSA, cross-sectional area; EMS, electrical muscle stimulation; LAW, lateral abdominal wall; LC, lumbopelvic control; RA, rectus abdominis; ST, superimposed technique.

\section{Results}

Table 2 presents the preintervention and postintervention results. There were no significant differences in the CSA of the RA (right-side mean change: -0.05 ; $95 \% \mathrm{CI},-0.31$ to 0.21 ; effect size: $0.003 ; P=.70$; left-side mean change: $-0.001 ; 95 \% \mathrm{CI},-0.28$ to 0.28; effect size, $0.000, P=.99$ ) or the LAW (right-side mean change: $-0.42 ; 95 \% \mathrm{CI},-0.88$ to 0.04 ; effect size: $0.068 ; P=.07$; left-side mean change: $-0.11 ; 95 \% \mathrm{CI},-0.69$ to 0.46 ; effect size: $0.003 ; P=.69$ ) on either side between groups. A significant difference was observed between premeasurement and postmeasurement of the CSA of the RA (right: $P<.001$, left: $P<.001$ ) and the LAW (right: $P<.001$, left: $P<.001$ ) on both sides. Figure 3 illustrates the significant differences between the premeasurement and postmeasurement in each group, based on post hoc analysis.

A significant difference was observed between groups for the double-leg lowering test (mean change: $0.05 ; 95 \%$ CI, 0.01 to 0.10 ; effect size: $0.10 ; P=.03$ ), but not between groups for the single-leg lowering test (mean change: $-0.005 ; 95 \% \mathrm{CI},-0.07$ to 0.06 ; effect size, $0.000 ; P=.88$ ). There were significant differences between the premeasurement and postmeasurement for the single-leg $(P<.001)$ and double-leg lowering tests $(P<.001)$.

Figure 3 shows the significant differences between the premeasurement and postmeasurement for each group (ST: $P=.03$, EMS: $P$ $=.01$ ), according to post hoc analysis of the single-leg lowering test data. Regarding the double-leg lowering test, a significant difference was observed between the premeasurement and postmeasurement in the ST group $(P<.001)$, but not in the EMS group $(P=.14)$.

\section{Discussion}

Abdominal and core muscle training has been highly emphasized for improving LC, preventing low back pain, and increasing physical performance in the clinical, sports, and fitness fields..$^{27,34}$ Of the 2 types of contractions, ST induces more pronounced neuromuscular adaptation than EMS training alone. ${ }^{20}$ However, EMS and VC together could lead to greater physiological adaptation than either contraction type alone. Our results indicate that 8 weeks of ST training of the abdominal muscles induced a greater increase in LC in the double-leg lowering test compared with EMS training alone. Thus, ST training is a good option for improving LC, abdominal muscle performance, and lumbopelvic stability.

Regarding muscle size, no significant difference in the CSA of the RA and LAW was noted between groups in this study postintervention. In previous studies, the integration of ST into training programs did not yield significant benefits over programs using EMS alone, with respect to the CSA of the quadriceps femoris. $5,51,52 \mathrm{In}$ addition, EMS and EMS combined with plyometric training have been shown to be more efficient than $\mathrm{VC}$ alone, but there was no significant difference between EMS and EMS combined with plyometric training on the CSA of the quadriceps femoris. ${ }^{53}$ Consistent with the principle of specificity, targeted manipulation of training variables is essential for maximizing exercise-induced muscle hypertrophy. ${ }^{54}$ Load has been shown to have an especially significant impact on muscle hypertrophy and is arguably the most important exercise-related variable for stimulating muscle growth. ${ }^{54}$ In the present study, the ST was in the form of a crunch exercise combined with EMS, which may produce a load insufficient to yield group differences. The analysis did not reveal a significant difference in the CSA of the RA or LAW between the groups, so we could not confirm that ST was superior to EMS for increasing the CSA of the RA and LAW; moreover, muscle activation was not measured (eg, via the twitch interpolation technique). Further investigations, including the assessment of muscle activation, would help to clarify whether there was an activation deficit prior to training, and whether EMS training could eliminate any such deficit in muscle fiber recruitment.

The anterior and posterior trunk muscles provide the control necessary for stabilizing the lumbar spine during limb movement. ${ }^{27,55,56}$ To accurately assess the effect of interventions on core muscle performance, and to develop more effective exercise programs, clinicians need an objective measure that can assess abdominal muscle performance and/or motor function. Current muscle tests for assessing trunk stability include the double-leg lowering test $^{57}$ and the single-leg lowering test. ${ }^{32,33,58}$ In the present study, the single-leg lowering exercise was categorized as grade 3.0 (highest possible grade $=5.0$ for double-leg lowering exercise), according to the lower abdominal muscle progression test. ${ }^{32,33}$ Thus, the doubleleg lowering test requires higher performance compared with the single-leg lowering test. 

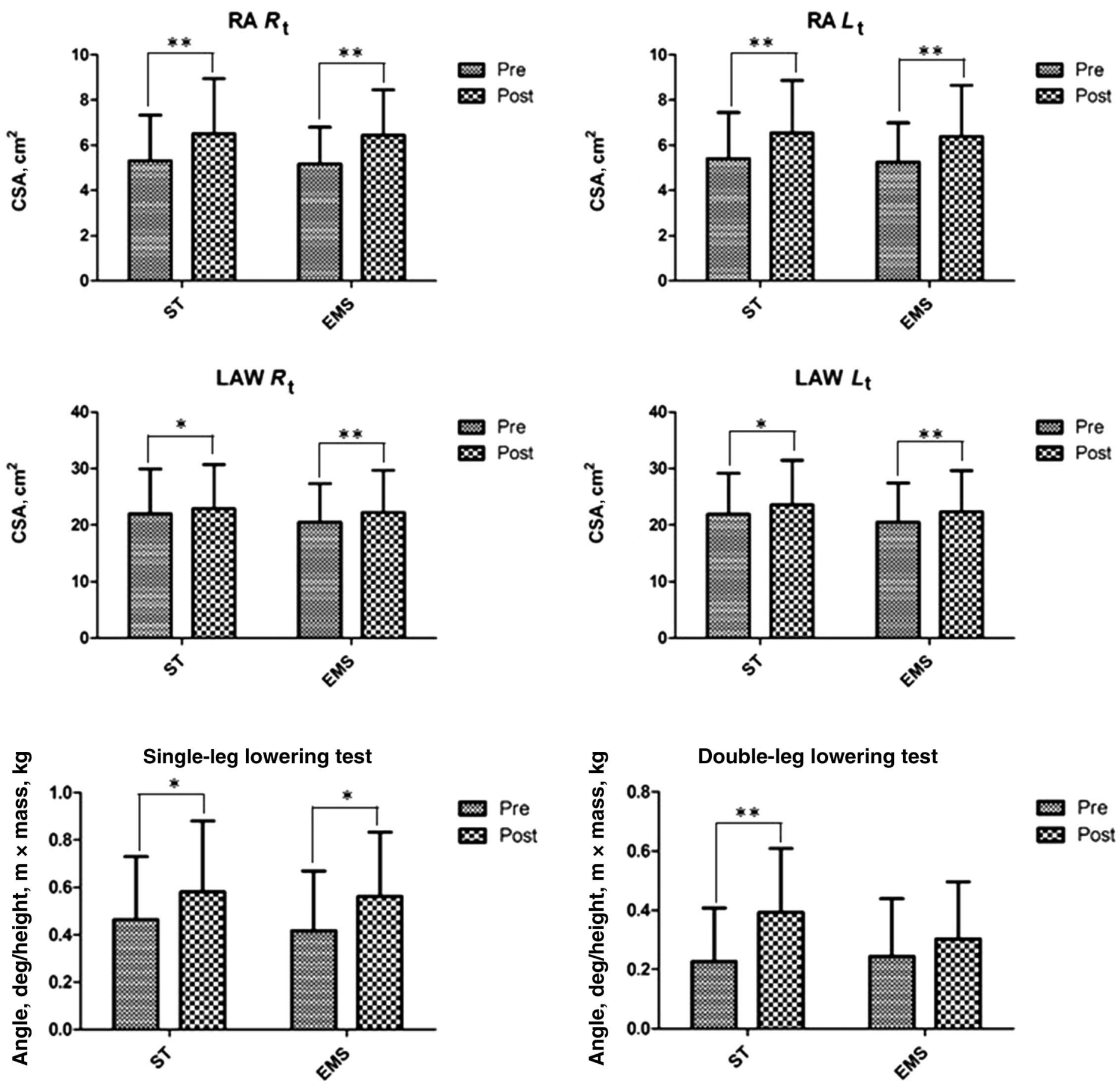

Figure 3 - Comparison of CSA of RA and LAW, and single-leg and double-leg loading tests among pre-EMS and post-EMS training sessions $(* P<.05 ; * * P<.01)$. CSA indicates cross-sectional area; EMS, electrical muscle stimulation; LAW, lateral abdominal wall; RA, rectus abdominis; ST, superimposed technique.

Regarding LC, the single-leg lowering test angle was significantly increased after 8 weeks of training in both groups, but a significant difference was not seen between groups. However, there was significant difference between groups in the double-leg lowering test; moreover, a significant increase from baseline was seen in the ST group, but not in the EMS group. No previous studies investigated the effect of ST or EMS training on muscle function or performance in healthy subjects. IO and TrA contraction are helpful for controlling intersegmental motion and responding to changes in posture and extrinsic loads. The IO and TrA contract together to increase intraabdominal pressure and provide support to the lumbar spine via the thoracolumbar fascia. ${ }^{59}$ The external oblique keeps anterior pelvic tilt in check. In the single-leg and double-leg lowering tests, the subject is asked to coactivate the deep stabilizing muscles; then, without moving the spine or pelvis during leg lowering, the load of the leg produces a rotary force on the pelvis 
and spine, such that the global muscles must contract to overcome this force and maintain the lumbopelvic position. ${ }^{29}$ By analyzing the data produced by these tests, we were able to ascertain whether ST and EMS affect parameters of lumbopelvic stability, such as neuromuscular and motor control, or cause cocontraction of global and local abdominal muscles. The significant difference between the groups in the double-leg lowering test, which requires a higher level of neuromuscular coordination compared with the single-leg lowering test, suggests that ST improves neural adaptation, coordination, and cocontraction by stimulating the muscles via $\mathrm{VC}$, where these muscles are not stimulated by EMS training alone.

The current study had several limitations. First, a control group is needed, with randomization between control, ST, and EMS groups, to allow comparison of the results. Second, it is difficult to generalize our results to various ages, because the current study focused on young men and women. Third, the subjects were normal individuals that were not patients with pain or diseases. Thus, further studies need to be performed on patients of various ages with musculoskeletal disease.

\section{Conclusions}

There were significant improvements in the CSA of the RA and LAW, as well as the LC, after the 8-week training program in both groups. There were no significant differences in the CSA of the RA or LAW, or the single-leg lowering test results, between groups. Therefore, EMS can be applied for improving the CSA of the RA and LAW in individuals who have difficulty with abdominal VCs due to surgery and immobility. The present study demonstrated that improvements in LC, as indexed by the double-leg lowering test, were greater in the ST training group than in the EMS training group. Thus, ST can be applied to improve LC in the context of athletic training and fitness.

\section{Acknowledgments}

The authors would like to thank all of the participants for their time and commitment to the present study. This study protocol was registered in Clinical Research information Service (KCT0002990) and was approved by the Institutional Review Board of Yonsei University, Wonju (1041849201802-BM-005-01). Brain Korea 21 PLUS Project (grant number: 201651-0009) sponsored by the Korean Research Foundation for Department of Physical Therapy in Graduate School, Yonsei University. The funder had no role in the design of the study and in writing the manuscript. The authors received financial and administrative support from the Yonsei University Research Fund (grant numbers: 2017-51-0498 and 2019-51-0094).

\section{References}

1. Lake DA. Neuromuscular electrical stimulation. Sports Med. 1992; 13(5):320-336. PubMed ID: 1565927 doi:10.2165/00007256199213050-00003

2. Gerovasili V, Stefanidis K, Vitzilaios K, et al. Electrical muscle stimulation preserves the muscle mass of critically ill patients: a randomized study. Crit Care. 2009;13(5):R161. PubMed ID: 19814793 doi:10.1186/cc8123

3. Cho HK, Jung GS, Kim EH, Cho YW, Kim SW, Ahn SH. The effects of neuromuscular electrical stimulation at different frequencies on the activations of deep abdominal stabilizing muscles. J Back Musculoskelet Rehabil. 2016;29(1):183-189. PubMed ID: 26444328 doi:10.3233/BMR-150638
4. Hasegawa S, Kobayashi M, Arai R, Tamaki A, Nakamura T, Moritani T. Effect of early implementation of electrical muscle stimulation to prevent muscle atrophy and weakness in patients after anterior cruciate ligament reconstruction. J Electromyogr Kinesiol. 2011; 21(4):622-630. PubMed ID: 21334221 doi:10.1016/j.jelekin.2011. 01.005

5. Currier D, Mann R. Muscular strength development by electrical stimulation in healthy individuals. Phys Ther. 1983;63(6):915-921. PubMed ID: 6856678 doi:10.1093/ptj/63.6.915

6. Porcari JP, Mclean KP, Foster C, Kernozek T, Crenshaw B, Swenson C. Effects of electrical muscle stimulation on body composition, muscle strength, and physical appearance. J Strength Cond Res. 2002;16(2):165-172. PubMed ID: 11991766

7. Hashida R, Takano Y, Matsuse H, et al. Electrical stimulation of the antagonist muscle during cycling exercise interval training improves oxygen uptake and muscle strength [published online ahead of print December 20, 2017]. J Strength Cond Res. PubMed ID: 29278576 doi:10.1519/JSC.0000000000002393

8. Maffiuletti NA. The use of electrostimulation exercise in competitive sport. Int J Sports Physiol Perform. 2006;1(4):406-407. PubMed ID: 19124897 doi:10.1123/ijspp.1.4.406

9. Seyri KM, Maffiuletti NA. Effect of electromyostimulation training on muscle strength and sports performance. Strength Cond J. 2011;33(1):70-75. doi:10.1519/SSC.0b013e3182079f11

10. Siff M. Applications of electrostimulation in physical conditioning: a review. J Strength Cond Res. 1990;4(1):20-26.

11. Hainaut K, Duchateau J. Neuromuscular electrical stimulation and voluntary exercise. Sports Med. 1992;14(2):100-113. PubMed ID: 1509225 doi:10.2165/00007256-199214020-00003

12. Ruther CL, Golden CL, Harris RT, Dudley GA. Hypertrophy, resistance training, and the nature of skeletal muscle activation. $J$ Strength Cond Res. 1995;9(3):155-159.

13. Hortobágyi T, Lambert J, Scott K. Incomplete muscle activation after training with electromyostimulation. Can J Appl Physiol. 1998; 23(3):261-270. doi:10.1139/h98-014

14. Duchateau J, Hainaut K. Training effects of sub-maximal electrostimulation in a human muscle. Med Sci Sports Exerc. 1988; 20(1):99-104. PubMed ID: 3343922 doi:10.1249/00005768198802000-00015

15. Laughman RK, Youdas JW, Garrett TR, Chao EY. Strength changes in the normal quadriceps femoris muscle as a result of electrical stimulation. Phys Ther. 1983;63(4):494-499. PubMed ID: 6601279 doi:10.1093/ptj/63.4.494

16. Cannon R, Cafarelli E. Neuromuscular adaptations to training. J Appl Physiol. 1987;63(6):2396-2402. PubMed ID: 3436873 doi:10.1152/ jappl.1987.63.6.2396

17. Lyle N, Rutherford O. A comparison of voluntary versus stimulated strength training of the human adductor pollicis muscle. J Sports Sci. 1998;16(3):267-270. PubMed ID: 9596361 doi:10.1080/02640419 8366795

18. Clamann HP, Gillies JD, Skinner RD, Henneman E. Quantitative measures of output of a motoneuron pool during monosynaptic reflexes. J Neurophysiol. 1974;37(6):1328-1337. PubMed ID: 4436703 doi:10.1152/jn.1974.37.6.1328

19. Knaflitz M, Merletti R, De Luca CJ. Inference of motor unit recruitment order in voluntary and electrically elicited contractions. $J$ Appl Physiol. 1990;68(4):1657-1667. PubMed ID: 2347805 doi:10.1152/ jappl.1990.68.4.1657

20. Paillard T, Noe F, Passelergue P, Dupui P. Electrical stimulation superimposed onto voluntary muscular contraction. Sports Med. 2005;35(11):951-966. PubMed ID: 16271009 doi:10.2165/ 00007256-200535110-00003 
21. Pichon F, Chatard J-C, Martin A, Cometti G. Electrical stimulation and swimming performance. Med Sci Sports Exerc. 1995;27(12): 1671-1676. PubMed ID: 8614324 doi:10.1249/00005768199512000-00014

22. Delitto A, Brown M, Strube M, Rose S, Lehman R. Electrical stimulation of quadriceps femoris in an elite weight lifter: a single subject experiment. Int J Sports Med. 1989;10(3):187-191. doi:10. 1055/s-2007-1024898

23. Dervisevic E, Bilban M, Valencic V. The influence of low-frequency electrostimulation and isokinetic training on the maximal strength of m. quadriceps femoris. Isokinet Exerc Sci. 2002;10(4):203-209. doi:10.3233/IES-2002-0105

24. Maffiuletti N, Gometti C, Amiridis I, Martin A, Pousson M, Chatard J-C. The effects of electromyostimulation training and basketball practice on muscle strength and jumping ability. Int J Sports Med. 2000;21(6):437-443. doi:10.1055/s-2000-3837

25. Bezerra P, Zhou S, Crowley Z, Brooks L, Hooper A. Effects of unilateral electromyostimulation superimposed on voluntary training on strength and cross-sectional area. Muscle Nerve. 2009;40(3):430437. PubMed ID: 19705423 doi:10.1002/mus.21329

26. Alon G, McCombe S, Koutsantonis S, et al. Comparison of the effects of electrical stimulation and exercise on abdominal musculature. $J$ Orthop Sports Phys Ther. 1987;8(12):567-573. PubMed ID: 18797021 doi:10.2519/jospt.1987.8.12.567

27. Marshall PW, Desai I, Robbins DW. Core stability exercises in individuals with and without chronic nonspecific low back pain. $J$ Strength Cond Res. 2011;25(12):3404-3411. PubMed ID: 22080309 doi:10.1519/JSC.0b013e318215fc49

28. Ebenbichler GR, Oddsson LI, Kollmitzer J, Erim Z. Sensory-motor control of the lower back: implications for rehabilitation. Med Sci Sports Exerc. 2001;33(11):1889-1898. PubMed ID: 11689740 doi:10.1097/00005768-200111000-00014

29. Richardson C, Jull G, Hodges P, Hides J. Therapeutic Exercise for Spinal Segmental Stabilization in Low Back Pain. London, UK: Churchill Livingstone; 1999:211-222.

30. Colston MA. Core stability, part 1: overview of the concept. Int J Athl Ther Train. 2012;17(1):8-13. doi:10.1123/ijatt.17.1.8

31. Richardson CA, Hodges P, Hides J. Therapeutic Exercise for Lumbopelvic Stabilization: A Motor Control Approach for the Treatment and Prevention of Low Back Pain. 2nd ed. Edinburgh, UK: Churchill Livingstone; 2004.

32. Haladay DE, Miller SJ, Challis JH, Denegar CR. Responsiveness of the double limb lowering test and lower abdominal muscle progression to core stabilization exercise programs in healthy adults: a pilot study. J Strength Cond Res. 2014;28(7):1920-1927. PubMed ID: 24343322 doi:10.1519/JSC.0000000000000336

33. Haladay DE, Denegar CR, Miller SJ, Challis J. Electromyographic and kinetic analysis of two abdominal muscle performance tests. Physiother Theory Pract. 2015;31(8):587-593. doi:10.3109/ 09593985.2015.1062945

34. Kibler WB, Press J, Sciascia A. The role of core stability in athletic function. Sports Med. 2006;36(3):189-198. PubMed ID: 16526831 doi:10.2165/00007256-200636030-00001

35. Hibbs AE, Thompson KG, French D, Wrigley A, Spears I. Optimizing performance by improving core stability and core strength. Sports Med. 2008;38(12):995-1008. PubMed ID: 19026017 doi:10.2165/ 00007256-200838120-00004

36. Comerford M, Mottram S. Kinetic Control: The Management of Uncontrolled Movement. Edinburgh, UK: Elsevier/Churchill Livingstone; 2012.

37. Cholewicki J, McGill SM. Mechanical stability of the in vivo lumbar spine: implications for injury and chronic low back pain.
Clin Biomech. 1996;11(1):1-15. doi:10.1016/0268-0033(95) 00035-6

38. Borghuis J, Hof AL, Lemmink KA. The importance of sensory-motor control in providing core stability. Sports Med. 2008;38(11):893916. PubMed ID: 18937521 doi:10.2165/00007256-20083811000002

39. Zazulak BT, Hewett TE, Reeves NP, Goldberg B, Cholewicki J. Deficits in neuromuscular control of the trunk predict knee injury risk: prospective biomechanical-epidemiologic study. Am J Sports Med. 2007;35(7):1123-1130. PubMed ID: 17468378 doi:10.1177/ 0363546507301585

40. Hammill RR, Beazell JR, Hart JM. Neuromuscular consequences of low back pain and core dysfunction. Clin Sports Med. 2008;27(3): 449-462. PubMed ID: 18503877 doi:10.1016/j.csm.2008.02.005

41. Moore C, Ceridan E, Schonard C, Marasa M, Shaib F, Holland J. Prevention of low back pain in sedentary healthy workers: a pilot study. Am J Med Sci. 2012;344(2):90-95. PubMed ID: 22173041 doi:10.1097/MAJ.0b013e3182364942

42. Linek P, Saulicz E, Wolny T, Myśliwiec A. Body mass normalization for ultrasound measurements of adolescent lateral abdominal muscle thickness. J Ultrasound Med. 2017;36(4):775-782. PubMed ID: 27943381 doi: $10.7863 /$ ultra.16.03086

43. Cheung CY, Ng GY. An eight-week exercise programme improves physical fitness of sedentary female adolescents. Physiotherapy. 2003;89(4):249-255. doi:10.1016/S0031-9406(05)60156-3

44. Faul F, Erdfelder E, Buchner A, Lang A-G. Statistical power analyses using G*Power 3.1: tests for correlation and regression analyses. Behav Res Methods. 2009;41(4):1149-1160. doi:10.3758/BRM.41. 4.1149

45. Hides JA, Boughen CL, Stanton WR, Strudwick MW, Wilson SJ. A magnetic resonance imaging investigation of the transversus abdominis muscle during drawing-in of the abdominal wall in elite Australian Football League players with and without low back pain. J Orthop Sports Phys Ther. 2010;40(1):4-10. PubMed ID: 20044702 doi:10.2519/jospt.2010.3177

46. Hides JA, Stanton WR, Freke M, Wilson S, McMahon S, Richardson CA. MRI study of the size, symmetry and function of the trunk muscles among elite cricketers with and without low back pain. Br J Sports Med. 2008;42(10):809-813. PubMed ID: 18065440

47. Zannotti CM, Bohannon RW, Tiberio D, Dewberry MJ, Murray R. Kinematics of the double-leg-lowering test for abdominal muscle strength. J Orthop Sports Phys Ther. 2002;32(9):432-436. PubMed ID: 12322809 doi:10.2519/jospt.2002.32.9.432

48. Krause DA, Youdas JW, Hollman JH, Smith J. Abdominal muscle performance as measured by the double leg-lowering test. Arch Phys Med Rehabil. 2005;86(7):1345-1348. PubMed ID: 16003662 doi:10. 1016/j.apmr.2004.12.020

49. Porcari JP, Miller J, Cornwell K, et al. The effects of neuromuscular electrical stimulation training on abdominal strength, endurance, and selected anthropometric measures. J Sports Sci Med. 2005;4(1):66. PubMed ID: 24431963

50. Cohen J. Statistical Power Analysis for the Behaviors Science. 2nd ed. New Jersey, NJ: Laurence Erlbaum Associates; 1988.

51. Paillard T, Lafont C, Costes-Salon M, Dupui P. Comparison between three strength development methods on body composition in healthy elderly women. J Nutr Health Aging. 2003;7(2):117-119. PubMed ID: 12679832

52. Nobbs L, Rhodes E. The effect of electrical stimulation and isokinetic exercise on muscular power of the quadriceps femoris. J Orthop Sports Phys Ther. 1986;8(5):260-268. PubMed ID: 18802225 doi:10.2519/jospt.1986.8.5.260 
53. Herrero AJ, Martin J, Martin T, Abadia O, Fernandez B, GarciaLopez D. Short-term effect of strength training with and without superimposed electrical stimulation on muscle strength and anaerobic performance: a randomized controlled trial. Part I. J Strength Cond Res. 2010;24(6):1609-1615. PubMed ID: 20508466 doi:10.1519/ JSC.0b013e3181dc427e

54. Schoenfeld BJ. The mechanisms of muscle hypertrophy and their application to resistance training. J Strength Cond Res. 2010; 24(10):2857-2872. PubMed ID: 20847704 doi:10.1519/JSC. 0b013e3181e840f3

55. Marshall P, Murphy B. Delayed abdominal muscle onsets and selfreport measures of pain and disability in chronic low back pain. $J$ Electromyogr Kinesiol. 2010;20(5):833-839. PubMed ID: 19853473 doi:10.1016/j.jelekin.2009.09.005
56. Silfies SP, Mehta R, Smith SS, Karduna AR. Differences in feedforward trunk muscle activity in subgroups of patients with mechanical low back pain. Arch Phys Med Rehabil. 2009; 90(7):1159-1169. PubMed ID: 19501348 doi:10.1016/j.apmr. 2008.10.033

57. Kendall FP, McCreary E, Provance P, Rodgers M, Romani W. Muscles: Testing and function, With Posture and Pain (Kendall, Muscles). Philadelphia, PA: Lippincott Williams \& Wilkins; 2005.

58. Sahrmann S. Diagnosis and Treatment of Movement Impairment Syndromes. St. Louis, MO: Mosby; 2001.

59. Akuthota V, Ferreiro A, Moore T, Fredericson M. Core stability exercise principles. Curr Sports Med Rep. 2008;7(1):39-44. PubMed ID: 18296944 doi:10.1097/01.CSMR.0000308663. 13278.69 